\title{
Investigando representações da presidenta Dilma Rousseff e do vice-presidente Michel Temer em capas de revistas nacionais sobre o impeachment
}

Investigating representations of president Dilma Rousseff and vice-president Michel Temer on national magazine covers about the impeachment

\author{
Fábio Alexandre Silva Bezerra \\ José Alves de Araújo Neto \\ DOI: $h$ ttp://dx.doi.org/10.5902/2176148531291
}

Resumo: Neste artigo, desenvolvemos uma investigação multimodal e crítica de representações de Dilma Rousseff e de Michel Temer em capas das revistas Veja e Carta Capital sobre o impeachment. Objetivamos decifrar sentidos construídos evidenciando discursos dominantes e marginais, a fim de revelar posicionamentos ideológicos dessas publicações. Resultados gerais demonstram forte teor ideológico nas duas publicações, retratando os mesmos fatos com foco, interpretações e objetivos diferentes. Tais textos multimodais ecoam posicionamentos políticos, ocultando sentidos que, muitas vezes, são apreendidos apenas inconscientemente por meio da repetição de certas representações em nosso cotidiano. Evidencia-se, assim, a relevância de se desvelar sentidos ocultos por meio da leitura crítica dos textos midiáticos.

Palavras-chave: Multimodalidade. Análise Crítica do Discurso. Impeachment. Mídia.

Abstract: In this paper, we have developed a multimodal and critical investigation of representations of Dilma Rousseff and Michel Temer in the covers of Veja and Carta Capital about the impeachment. We aim to unveil constructed meanings by demonstrating dominant and marginal discourses in order to reveal ideological stances of these publications. Overall results demonstrate strong ideological content in both publications, portraying the same facts with different focus, interpretations and objectives. Such multimodal texts echo political positions, concealing meanings that are often only unconsciously grasped through the repetition of certain representations in our daily lives. Thus, the relevance of revealing hidden meanings through the critical reading of media texts is evidenced.

Keywords: Multimodality. Critical Discourse Analysis. Impeachment. Media. 
Fábio Alexandre

Silva Bezerra

José Alves de Araújo Neto

\section{Introdução}

Em 26 de outubro de 2014, Dilma Rousseff é declarada vencedora do segundo turno presidencial pelo Tribunal Superior Eleitoral e, em 01 de janeiro de 2015 , toma posse como a primeira mulher a ser eleita presidenta para um segundo mandato na história do país. Tal vitória, com 54.501.118 votos, entretanto, não se traduziu em governabilidade para si e seu partido. Seu governo foi abalado, desde seus primeiros dias, pela falta de articulação política com o parlamento e por uma oposição que demostrava não aceitar o resultado das eleições. A Operação Lava-Jato, a crise na Petrobrás e a crise econômica se mostraram fatores decisivos em um cenário que evidenciava a polarização da população brasileira.

Em 02 de dezembro de 2015, 336 dias após a posse da presidenta, Eduardo Cunha, o então presidente da Câmara dos Deputados, inicia um processo de impeachment contra a presidenta Dilma Rousseff, que seria encerrado no dia 31 de agosto de 2016, com a condenação final da presidenta no Senado Federal. A condenação, contudo, não uniu o país, tendo a polarização de opiniões sido mantida e, talvez, até intensificada, visto que a narrativa sobre a existência de um golpe ou de um legítimo processo de impeachment, construída ao longo dos últimos anos, permaneceu alvo de discussões. Durante todo o processo, revistas de circulação nacional representaram os eventos de forma alarmante, algumas como Veja, IstoÉ e Época alinhadas à narrativa de um impeachment emergencial e necessário, e outras como Carta Capital e Piauí buscando advertir a população acerca de um golpe parlamentar que estaria em curso. Vale ressaltar que a tiragem semanal das três primeiras publicações mencionadas foi largamente mais ampla do que a das duas últimas.

Nessecontexto,éprementealeituracrítica dessestextos multimodais no sentido de entender como eles podem ter influenciado os atores sociais nas mais diversas esferas de atuação, visto que o uso da linguagem verbal e/ou visual está intimamente relacionado às ações do nosso cotidiano, que assume especial relevância ao lembrarmos, como destacado por Charadeau (2006, p. 252-253), que "todo ato de linguagem é um agir sobre o outro", é o "exercício de um poder". Com esse objetivo geral, partimos de conceitos teórico-analíticos propostos pela Gramática Visual de Kress e van Leeuwen (2006) e pela Análise Crítica do Discurso de Fairclough (1995, 2015[1989]), para fundamentar a investigação de representações da presidenta Dilma Rousseff e do então vice-presidente Michel Temer em capas de revista nacionais sobre o processo de impeachment. 
Os objetivos específicos da presente pesquisa são: 1) desvendar os sentidos construídos nas capas de revistas analisadas para que seja possível compreender alguns discursos dominantes e marginais presentes nesse momento histórico; 2) estabelecer como o texto multimodal nas capas de revistas escolhidas podem ocultar sentidos que, muitas vezes, são apenas inconscientemente apreendidos por meio da repetição de certas representações em nosso cotidiano; 3) revelar a curva ideológica informada pela política editorial de cada uma das publicações analisadas, que poderá ser compreendida a partir da comparação entre as capas e, destacadamente, da leitura das matérias correspondentes, visto que a análise de elementos microestruturais também deve ser reforçada pela inclusão de considerações da macroestrutura na qual tais textos se inserem.

Ao investigar tais representações, podemos aferir que elas utilizam Investigando representações da presidenta DilmaRousseffe dovice-presidente Michel Temer em capas de revistas nacionais sobre o impeachment elementosvisuais etextosverbaisdepertinentevalornarrativo.Percebemos, assim, a necessidade de advertir os leitores acerca da importância de uma perspectiva de leitura multimodal crítica (BEZERRA; NASCIMENTO; HEBERLE, 2010) capaz de identificar e interpretar os elementos discursivos verbais e não verbais presentes nessas capas de publicações de grande circulação nacional e/ou de grande influência política. Tal advertência representa um esforço no sentido de evidenciar os funcionamentos discursivos imbricados nos textos em análise, especialmente tendo-se em vista que, segundo a pesquisa "Retratos da Leitura no Brasil" (FAILLA, 2016), $67 \%$ da população brasileira jamais recebeu qualquer incentivo à leitura.

Cientes da necessidade de leitura e, sobretudo, de leitura crítica, assim como da polarização política e ideológica atual, desenvolvemos esta pesquisa que busca refletir sobre um recorte do estado presente da mídia impressa brasileira e incentivar uma leitura mais crítica a seu respeito, visto que, devido à contínua expansão dos meios midiáticos e de sua influência política, social e econômica, o letramento crítico da mídia (KELLNER; SHARE, 2008) é um imperativo para a democracia participativa. Para tal, selecionamos duas publicações dentre as de maior tiragem nacional: Veja e Carta Capital, com o objetivo de realizar uma investigação multimodal discursiva baseada em publicações amplamente conhecidas por apresentar, em geral, visões bastante diferentes sobre as mesmas temáticas, i.e. um discurso e um contradiscurso.

Dessa maneira, é indispensável um debate envolvendo os produtores de conteúdo e os usuários dessas mídias, com o intuito de questionar essa naturalização de um marcado teor politico e ideológico, sobretudo nos 
Fábio Alexandre

Silva Bezerra

José Alves de

Araújo Neto tempos atuais em que a mídia impressa se encontra sofrendo inúmeros ataques políticos e uma crescente perda de credibilidade e de espaço frente aos avanços da internet e dos produtores de conteúdo independente.

Partimos, agora, para a explicitação dos conceitos teórico-analíticos básicos que sustentam as análises a serem apresentadas. Por questões de limitação de espaço, não será possível utilizar imagens para ilustrar cada conceito a seguir, os quais poderão, contudo, ser mais claramente apreendidos na leitura das análises multimodais desenvolvidas em seguida.

\section{Fundamentação teórica}

\subsection{A gramática visual}

A Gramática Visual de Kress e van Leeuwen (2006) desempenha aqui um papel importante, servindo de base tanto para a leitura crítica de imagens quanto para a compreensão do processo de construção de tais imagens e sentidos. Para tal, esses autores descrevem os significados multimodais em termos de três campos semânticos, assim como propõem Halliday e Matthiessen (2004), quais sejam: 1) a metafunção representacional, que se caracteriza pela representação de ações e de eventos que envolvem participantes em determinado contexto situacional; 2) a metafunção interacional, que enfatiza as relações criadas entre o texto multimodal e seus leitores; 3 ) a metafunção composicional, que descreve como as representações e as relações são organizadas em um texto coerente e coeso, destacando questões de posicionamento e de caracterização dos elementos que compõem a imagem.

A metafunção representacional é dividida em representações narrativas e conceituais. A primeira é caracterizada pela presença de participantes envolvidos em um evento, vetores (indicando movimento) e pano de fundo, podendo ser percebida pela presença de quatro tipos de processos: $\mathrm{o}$ acional (transacional $=2$ participantes representados + vetor ou não transacional = 1 participante representado); o reacional (aqui o vetor está sempre correspondendo à linha do olhar); o mental (balão de pensamento); o verbal (balão de fala).

Já a representação conceitual simboliza descrições e classificações. Suas características principais são: organização dos participantes envolvidos em taxonomias explícitas ou implícitas, e sua apresentação, em uma relação parte/todo, ausência de vetores (portanto, não apresentando movimento), ausência ou menor detalhamento do pano 
de fundo. Seus processos são: classificacional (taxonomias explícitas ou não); analítico (parte/todo); simbólico (presença de elemento atribuindo valor simbólico ao texto multimodal).

A metafunção interacional, por sua vez, possui quatro componentes, quais sejam: contato (podendo ser de demanda, se o olhar do participante representado estiver voltado para o leitor, ou de oferta, se o olhar não estiver focado no leitor); distância social (íntimo, social ou impessoal); atitude (envolvimento ou distanciamento, baseados no ângulo em que a imagem é mostrada: frontal para envolvimento e oblíquo para distanciamento); poder: ângulo alto (poder do observador), nível do olhar (igualdade) e ângulo baixo (poder do participante representado).

Por fim, a metafunção composicional aborda três aspectos: valor da informação, tratando da disposição específica de elementos na imaInvestigando representações da presidenta DilmaRousseffe dovice-presidente Michel Temer em capas de revistas nacionais sobre o impeachment gem, conferindo-lhe determinados valores (lado esquerdo = informação dada/conhecida / área direita: informação nova / área superior = informação ideal / área inferior = informação real / posição central = informação principal) / posição marginal = informação acessória); enquadramento: presença ou não de molduras que (des)conectam os elementos na imagem; saliência, que descreve as estratégias escolhidas para atrair a atenção para determinados elementos da composição (tamanho, cor, posição, contraste).

Em seguida, são descritos conceitos básicos dos estudos críticos do discurso que darão suporte especialmente para a análise do texto verbal e de sua relação com o texto imagético.

\subsection{A Análise Crítica do Discurso}

A Análise Crítica do Discurso (ACD) investiga a linguagem em uso dentro de um contexto social para revelar, por exemplo, construções ideológicas, visto que é por meio da linguagem que agimos no mundo. Sendo assim, as práticas discursivas situadas, ou seja, o papel social que cada um de nós representa por meio da linguagem revela as nossas várias identidades e crenças (CALDAS-COULTHARD, 2008). Nesse sentido, Magalhães $(2005$, p. 3) ressalta que "a ADC estuda textos e eventos em diversas práticas sociais, propondo uma teoria e um método para descrever, interpretar e explicar a linguagem no contexto sócio-histórico".

Assim, a ACD, partindo de textos específicos, preocupa-se em analisar práticas sociais e relações de poder que subjazem o discurso. Fortemente influenciada por suas leituras de Gramsci, Althusser, Bour- 
Fábio Alexandre

Silva Bezerra

José Alves de Araújo Neto dieu e Foucault, a contribuição de Fairclough (1995, 2015[1989]) para os estudos críticos da linguagem é bastante significativa, tendo proposto uma análise crítica do discurso que se constitui como norte teórico-metodológico a partir da compreensão do evento discursivo em três dimensões, quais sejam: o texto em si, as práticas discursivas e as práticas sociais. Sendo assim, todo texto - seja ele falado, escrito ou multimodal - transmite uma mensagem (por meio de escolhas lexicais, gramaticais, de coesão e de estrutura) que, ao ser lida, promove uma interação por meio da mobilização de práticas discursivas (foco em questões de coerência, intertextualidade e interdiscursividade). A prática social, por sua vez, é uma dimensão mais abrangente, que oportuniza considerações sobre relações de poder e de classe, por exemplo, a partir de discussões sobre ideologias que perpassam o texto em análise.

Dessa maneira, a ACD se organiza a partir de algumas perspectivas (MEURER, 2005), quais sejam: 1) a linguagem é vista como prática social, isto é, o discurso presente no texto influencia e é influenciado por quem o lê; 2) a linguagem tem poder constitutivo, pois, através dela, identidades e realidades sociais são criadas, e os textos trazem rotinas sociais, as quais são retratadas no discurso; 3) relações de poder perpassam o discurso, oportunizando, assim, a manutenção do poder hegemônico de uma classe social em detrimento de outra que não disponha dos mesmos recursos materiais e simbólicos; 4) entrelaçados no discurso, há sempre ideologias e relações de poder subjacentes.

A ACD, portanto, além de ser uma teoria e um método de análise, busca conscientizar os indivíduos quanto às relações existentes entre o discurso e as estruturas sociais. Em seu texto, Meurer (2005, p. 94) explica que a ACD é uma forma de luta por mudanças sociais e que

\footnotetext{
Fairclough acredita que uma vez que alguém se torne consciente do valor ideológico de determinado discurso, pode resistir a ele, e o aspecto ideológico pode consequentemente perder ou diminuir seu efeito. A compreensão do papel da linguagem como prática social pode cooperar para a emancipação de grupos menos privilegiados.
}

Sendo assim, é evidente a necessidade de considerarmos questões que vão além do nível textual ao discutirmos relações de poder estabelecidas pela mídia. Portanto, com base nos dados obtidos pela 
análise multimodal (texto), também deve haver a discussão das práticas discursivas nas quais o texto analisado se insere, bem como das implicações ideológicas e de poder das práticas sociais com as quais o texto se relaciona (RESENDE; RAMALHO, 2006).

Portanto, poder, história e ideologia são conceitos indispensáveis para a Análise Crítica do Discurso, pois todo discurso é historicamente produzido e interpretado, está impregnado de ideologias e desafia ou contribui para a manutenção do status quo. Para van Dijk (2002, p. 15), "provavelmente mais do que qualquer outro tipo de discurso, o discurso político é eminentemente ideológico", sendo, então, fundamental para o cidadão em uma democracia a análise de tais discursos, pois, do contrário, estariam condenados apenas à repetição de práticas coletivas naturalizadas e/ou a críticas sem fundamento.

Nesse contexto, e por sabermos que os discursos construídos pelas duas publicações analisadas estão marcados por questões ideológicas a partir de posições políticas particulares, é essencial que falemos um pouco sobre o discurso político, especialmente ao considerarmos que o "discurso não é simplesmente aquilo que traduz as lutas ou os sistemas de dominação, mas aquilo por que e pelo que se luta, o poder do qual nos queremos apoderar" (FOUCAULT, 1996, p. 10).

\subsection{0 discurso político}

Ao falar sobre o tratamento dado ao discurso político, Charadeau (2006) propõe uma perspectiva focalizada na linguagem a partir da descrição de três elementos essenciais: a opinião pública, as mídias e os atores políticos. No entanto, o termo "discurso político" pode se referir a distintos contextos e atores sociais dependendo da perspectiva adotada. Devemos, portanto, explicitar a visão adotada neste artigo.

Como destaca van Dijk (1997, p. 13), "não são apenas as ações políticas oficiais e profissionais e os políticos que estão envolvidos na política”, ou seja, o processo político e suas ações diárias também “envolvem os cidadãos e eleitores, membros de grupos de pressão, manifestantes e dissidentes". Dessa maneira, esse conceito mais abrangente de política também implica uma visão mais ampla de discurso político. Essa característica de abrangência do discurso político, como alerta o autor, assume importância mais evidente quando consideramos que essas ações políticas também são práticas discursivas, visto que, por meio de textos e falas, o discurso desempenha funções e tem implicações específicas. 
Fábio Alexandre
Silva Bezerra

José Alves de Araújo Neto

Essa perspectiva interacional, que vai além dos políticos para incluir outros atores sociais, parece ser mais apropriada quando se almeja a superação de relações de dominação, bem como uma melhor compreensão acerca dos mecanismos que podem gerar, por exemplo, abusos de poder por meio das práticas de linguagem (multimodal) que permeiam diversos contextos da vida em sociedade, dando destaque para "as condições discursivas e consequências da desigualdade social e política que resulta de tal dominação" (VAN DIJK, 1997, p. 11).

Charadeau (2006, p. 267) afirma ainda que "o campo político é um domínio onde se movem relações de força simbólicas para a conquista e a gestão do poder". Em vista disso, é vital estarmos alertas para as representações que as mídias constroem, especialmente sobre assuntos de interesse social e de repercussão nacional, tal como a análise, neste artigo, das representações de dois dos atores sociais de maior destaque no período histórico em questão, a fim de avaliarmos de maneira crítica o papel que a mídia desempenhou no processo de impeachment. Toda essa arquitetura de análise do discurso político se baseia em uma "concepção da linguagem política que resulta dialeticamente de dois eixos que determinam dois tipos de atividade social" (CHARADEAU, 2006, p. 257), quais sejam

\footnotetext{
- a do dizer político, do debate de ideias no vasto campo do espaço público, lugar onde se trocam opiniões;

- a do fazer político, no campo mais restrito do espaço onde se tomam decisões e se realizam atos.
}

Essas atividades sociais podem ser identificadas nas capas de revistas analisadas, pois há posicionamentos sendo construídos por meio da linguagem verbal e visual, por meio de um embate discursivo com outras visões sobre o mesmo tema, e também há ações que decorrem de tais dizeres políticos, como, por exemplo, o aumento de policiamento ostensivo durante manifestações de rua devido a pressões de determinados grupos e atores sociais. Fica evidente, assim, que o dizer e o fazer políticos estão imbricados de maneira incontestável.

Em suma, a análise multimodal do discurso político "deve se concentrar em como os discursos, como formas de representação, fornecem aos agentes motivos para ação" (FAIRCLOUGH; FAIRCLOUGH, 2012, p. 1), ou seja, os discursos apresentam grande eficiência para influen- 
ciar como crises serão narradas e interpretadas, especialmente os discursos construídos pela mídia.

Tendo descrito os conceitos teórico-analíticos que permeiam este estudo, passamos à descrição dos procedimentos metodológicos que o orientaram.

Investigando representações da presidenta DilmaRousseffe

\section{Metodologia}

Para a realização da pesquisa, primeiramente buscamos informações com o Instituto Verificador de Comunicação acerca das revistas mais vendidas no país. Selecionamos, então, a Veja, por ser a mais vendida no Brasil e pelo seu discurso pró-impeachment. Buscando um ponto de vista divergente, i.e., um contradiscurso, optamos, então, pela Carta Capital, com números bem mais modestos, mas que, dentre as opções de dovice-presidente Michel Temer em capas de revistas nacionais sobre o impeachment mídia contrária ao impeachment, exerce um papel de grande destaque. Em seguida, delimitamos o número de capas que seriam analisadas, no total de seis (6), a partir do recorte histórico de: 1) abertura do processo de impedimento na Câmara dos Deputados; 2) depois da votação na Câmara dos Deputados e, por fim, 3) depois da votação no Senado Federal.

A seguir, realizamos a análise multimodal com base na Gramática Visual. Devemos explicar, neste momento, que os dados aqui apresentados, por limites de espaço, referem-se primordialmenteà metafunção representacional. Serão feitos apenas comentários eventuais sobre os significados interacionais e composicionais. Além disso, por questões editoriais, as imagens deste artigo estão reproduzidas em preto e branco na versão impressa, sugerimos, portanto, caso seja necesário, que consultem as páginas oficiais das respectivas revistas (vide referencias finais) para que tenham acesso à versão original em cores.

Depois, foi feita a análise crítica do discurso político. Com os resultados obtidos, refletimos sobre o papel da mídia em nossa sociedade, apontando para questões positivas, mas também questões negativas que não são comumente discutidas. Por fim, os resultados obtidos são apresentados e discutidos na seguinte seção.

\section{Resultados e discussão}

As capas são analisadas, em um primeiro momento, no plano multimodal, e, em um segundo momento, a partir de uma análise crítica discursiva. Diante da importância do processo de impeachment para toda a sociedade brasileira, e considerando o impacto das representações imagéticas e verbais em capas de revista de grande circulação, realizamos 
Fábio Alexandre

Silva Bezerra

José Alves de Araújo Neto as análises a seguir com a finalidade de discutir e investigar como tais veículos midiáticos construíram as imagens de Dilma Rousseff e de Michel Temer durante e após esse momento histórico recente.

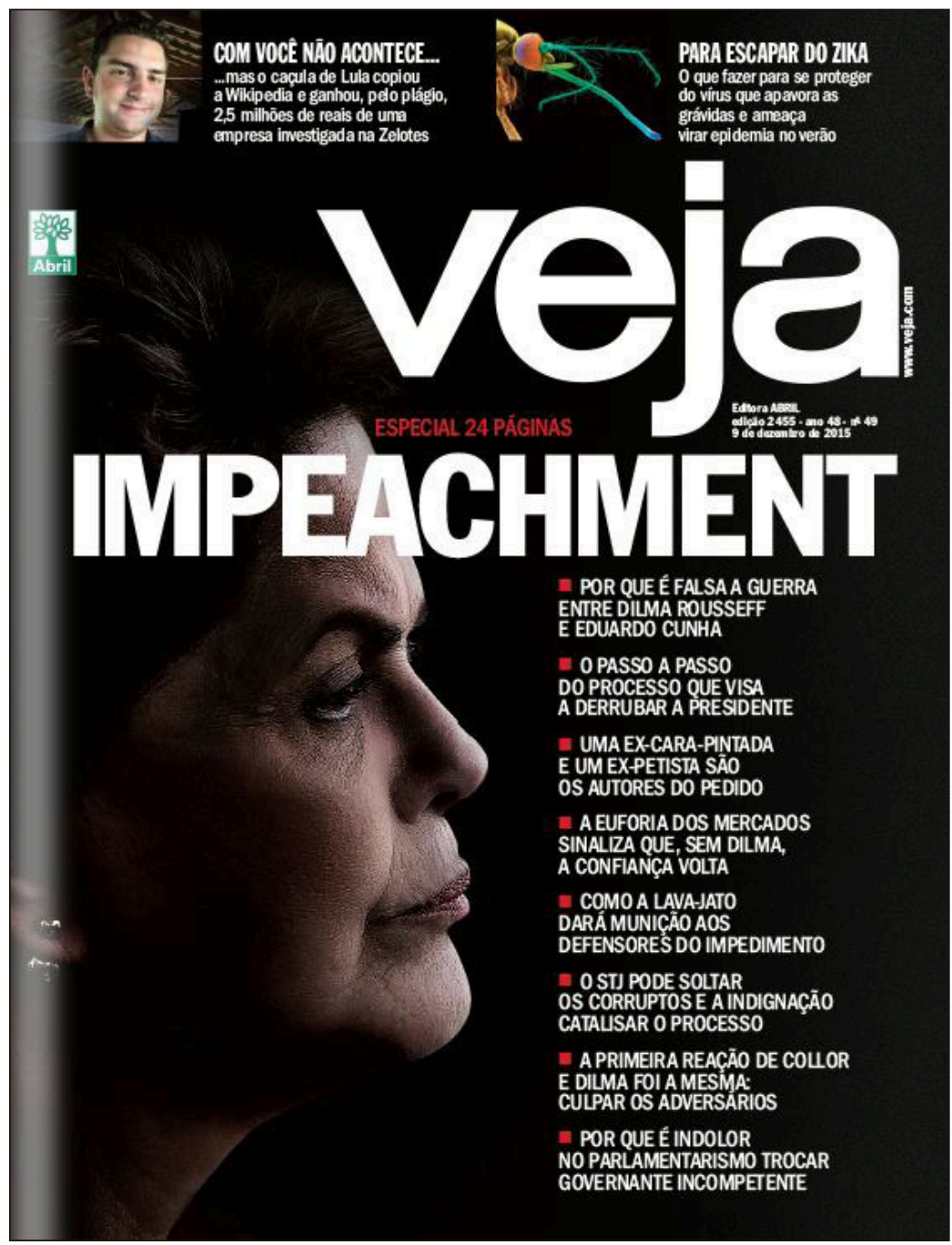

Figura 1: Capa 1 da Veja

Fonte: Página da revista na internet

A primeira capa a ser analisada (Fig. 1) mostra Dilma olhando fixamente para algo não revelado (processo reacional não transacional), com expressão séria. A presidenta é representada observando algo possivelmente ainda em curso, com foco nos próximos passos e um evento ainda não finalizado: provavelmente o impeachment da manchete estaria se aproximando, 
o que explicaria também a expressão séria. Sendo assim, vemos uma representação narrativa com foco no participante único reagindo a um elemento desconhecido, sem qualquer informação imagética sobre circunstâncias.

Além da narrativa, também podemos constatar a presença de determinados conceitos sendo criados. Dilma é representada apenas por sua face direita em um contraste entre luz e sombras, o que caracteriza um processo analítico. Isso ocorre no contexto de escuridão total no pano de fundo, marcando um processo simbólico sugestivo, visto que essa cor densa adiciona valores à representação por meio de compreensões culturais compartilhadas. Tais elementos podem remeter à situação de incertezas, de crise econômica e política enfrentada pelo país. Como afirma Wodak (2015), narrativas populistas da direita política alcançam sucesso, muitas vezes, por meio da manipulação dos fatos para criar uma atmosfera de medo na população, especialmente por meio da criação de culpados únicos para a situação temida: nesse caso, Dilma e seu partido.

Essa análise se confirma ao considerarmos o texto verbal, que constrói de maneira evidente uma imagem negativa da então presidenta da República por meio de uma série de afirmações, dentre as quais podemos destacar as seguintes: o conflito entre Dilma e Eduardo Cunha (então presidente da Câmara dos Deputados, agente político que autoriza a instauração do processo de impeachment) era uma farsa, ocultando suas reais motivações; o fato de que a legitimidade do pedido de impeachment está sendo construída pelas escolhas lexicais de representar seus autores como "ex-cara-pintada" (referindo-se aos jovens que foram às ruas em 1992 para pedir o impeachment do ex-presidente Fernando Collor de Melo) e "ex-petista", questões que serão discutidas mais adiante.

Com tais escolhas, a revista Veja, em sua edição especial de 24 páginas sobre o impeachment, constrói por meio do texto multimodal um cenário particular acerca do momento político brasileiro, representando Dilma Rousseff como uma figura envolta em dúvidas e preocupações, e o impeachment como a saída ideal para a crise.

Em diversas esferas da sociedade, mas principalmente na política, a posse da narrativa ${ }^{1}$ é fundamental, pois, apesar de sabermos que as divi-

1 Posse Narrativa seria um aspecto discursivo próprio da mídia mainstream que busca consolidar um único discurso como verdadeiro e definitivo, quase sempre aliado ao poder econômico e politico das nações hegemônicas. Em uma palestra TED, a escritora e ativista nigeriana Chimamanda Adichie nos alerta acerca dos perigos que tal posse narrativa representa para a cultura e a identidade de países e populações à margem dos centros hegemônicos de poder (Disponível em: <https://www.youtube.com/ watch?v=D9Ihs241zeg>). Acesso em: 16 ago 2018. 
Fábio Alexandre

Silva Bezerra

José Alves de Araújo Neto

sões entre "bem" e "mal", "correto" e "errado", "golpe" e "impeachment" serem bem estabelecidas, na prática tais distinções podem não ser tão claras. Aliado ao problema da posse narrativa, também nos deparamos com complicações resultantes da chamada Era da Informação, onde o excesso de notícias causaria, na verdade, um depauperamento da capacidade do indivíduo de fazer uma leitura crítica e seletiva. Entretanto, tais questionamentos não são exclusivos do século XXI, pois o excesso de informação já era uma questão, por exemplo, desde a França do século XVIII. Segundo o livro Os Dentes Falsos de George Washington ${ }^{2}$, do historiador norte-americano Robert Danton, os "mexericos" e os impressos voltados à bisbilhotice da vida da realeza ocupavam grande parte do comportamento comunicacional e geravam uma série de discussões acerca do grande fluxo de informações. Sobre o assunto, o engenheiro matemático estadunidense Claude Shannon (1916-2001), autor do livro Teoria Matemática da Comunicação, afirma que o que vivemos não pode ser considerado como uma "era de informação", pois informação seria tudo aquilo que reduz incertezas, e o que se vê atualmente é o oposto.

Diante desse contexto, a Análise Crítica do Discurso (ACD) assume, então, o difícil papel (principalmente em tempos de "pós-verdade") 3 de refletir sobre as narrativas e de compreender que elas estão a todo momento sendo construídas e disseminadas (com base ou não em fatos). Analisar criticamente passa por retirar o véu das palavras (e das imagens), bem como perceber as vozes e intenções que ecoam no discurso.

Quanto ao texto verbal, na Figura 1, devemos dar atenção especial para as afirmações listadas do lado direito da capa (informações novas a serem apresentadas, em termos composicionais), tais como: "Por que é falsa a guerra entre Dilma Rousseff e Eduardo Cunha”. Segundo a publicação, Eduardo Cunha teria afirmado que o governo tentou até o último minuto um acordo para salvar a presidenta do impeachment. Existe aqui uma tentativa de modificar o discurso predominante na época, que colocava Cunha e Dilma como antagonistas e afirmava que a abertura do processo de impeachment havia sido realizada como uma espécie de vingança, pois o mesmo haveria sido "traído" pelo governo ao não ser "blindado" contra a operação Lava-Jato.

\footnotetext{
2 “Os Dentes Falsos de George Washington: Um guia não convencional para o século XVIII" é um livro publicado em 2005, que discute a disseminação da palavra oral e impressa nos meios populares e intelectuais franceses do século XVIII.

3 Segundo os dicionários Oxford, "pós-verdade se relaciona ou denota circunstâncias nas quais fatos objetivos têm menos influência em moldar a opinião pública do que apelos à emoção e crenças pessoais”.
} 
"Uma ex-cara-pintada e um ex-petista são os autores do pedido". Aqui a Veja se refere a Janaína Paschoal e a Hélio Bicudo, tentando legitimar o pedido ao afirmar que Janaína (jurista e professora de Direito) foi uma cara-pintada e, portanto, possui uma trajetória de luta política e ativismo. Já Bicudo, por ter sido um importante elemento do Partido dos Trabalhadores (PT), estaria informado do que ocorre dentro do partido, dando, assim, mais respaldo ao pedido de abertura do processo.

"A primeira reação de Dilma e Collor foi a mesma: culpar os adversários". Há uma narrativa sendo construída, uma tentativa de representar dois momentos históricos como sendo iguais, o que, a princípio, fortaleceria a posição de que Dilma deve ser retirada da presidência, já que o mesmo ocorreu com Collor de Melo. No entanto, os impedimentos de Collor e de Dilma possuem divergências. Investigando representações da presidenta DilmaRousseffe dovice-presidente Michel Temer em capas de revistas nacionais sobre o impeachment A primeira diz respeito às descobertas durante as investigações, no processo do ex-presidente Collor, quando foram identificadas diversas contas fantasmas operadas por seu tesoureiro de campanha, assim como o desvio de verba de obras públicas e a de que sobras da campanha eleitoral de 1989 estavam sendo usadas para pagar despesas pessoais de Collor. Nas investigações envolvendo a presidenta, ela não se tornou ré ou mesmo foi investigada acerca de qualquer processo que diga respeito à prática de corrupção.

Outra afirmação é a de que, sem Dilma, o mercado irá reagir positivamente. Tal afirmação pretende associar a melhora da economia com a saída de Dilma do poder. Sabemos, contudo, que tal melhora não pode ser garantida apenas pela "euforia do mercado"; além disso, um rompimento de tal magnitude poderia causar reflexos inversos na economia por gerar incertezas e instabilidade política. Percebemos, assim, que a intenção desta capa é favorecer o processo de impeachment, mostrando Dilma como causa da crise. Sendo assim, acreditamos que, se ela for deposta, o cenário tenderá necessariamente a melhorar.

A narrativa é simples e, portanto, fácil de ser disseminada e consumida como "verdade" por grande parte da população brasileira. Há uma vilã e há uma solução, que é apresentada por agentes sociais que se distanciam de qualquer envolvimento com aquela. Mas tal narrativa, apesar de ganhar uma dimensão gigantesca ao ser vinculada pela revista de maior circulação do Brasil, não é a única a ser considerada em relação ao impeachment. Existem outras vozes em ação, como a da Carta Capital, que analisaremos a seguir. 
Fábio Alexandre

Silva Bezerra

José Alves de Araújo Neto

\section{EDIÇÃO ESPECIAL DA CRISE}

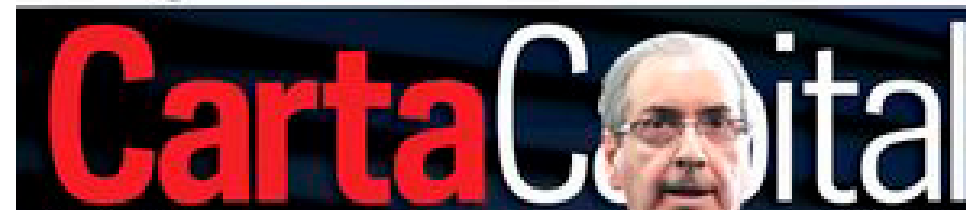

Hatcatas.
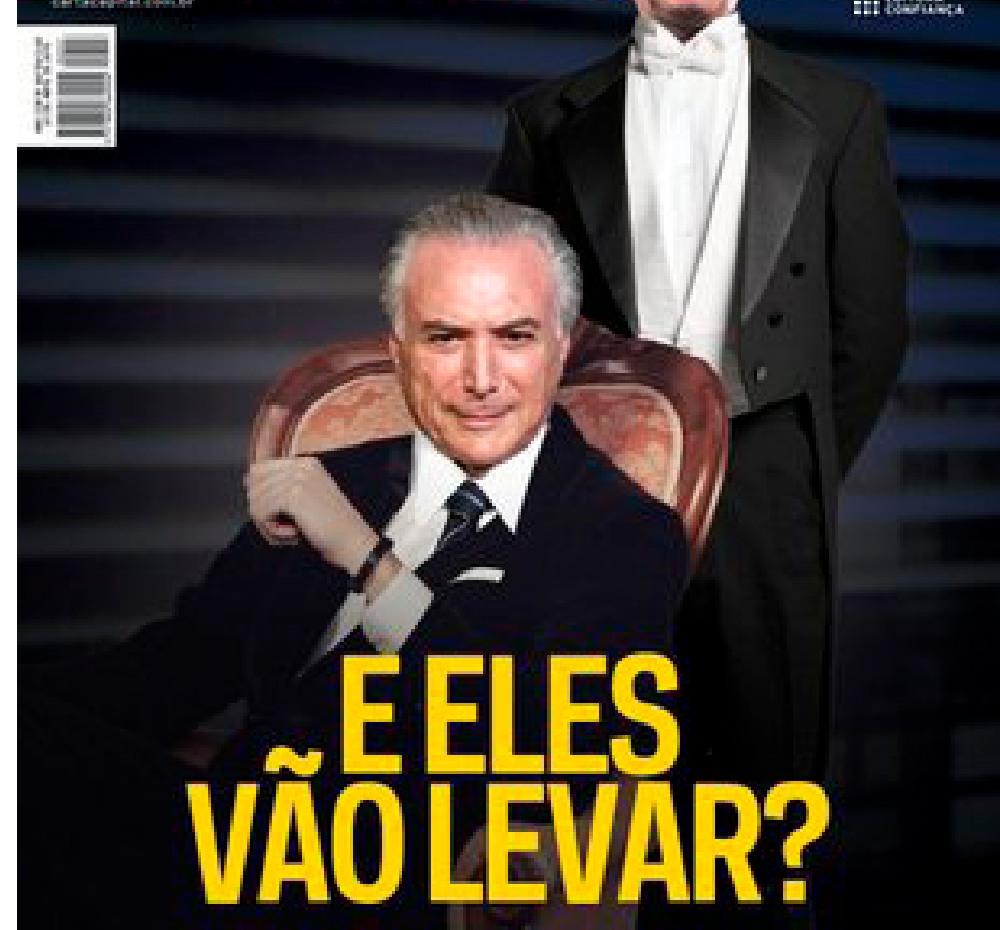

Figura 2: Capa 1 da Carta Capital

Fonte: Página da revista na internet

Nesta capa da Carta Capital (Fig. 2), podemos ver que há, também, uma escolha pelo tom sombrio, mas aqui os protagonistas são outros. 0 vice-presidente e o presidente da Câmara dos Deputados aparecem em destaque e acompanhados de uma questão: "E eles vão levar?". Portanto, podemos observar que o viés é diferente. Enquanto a edição da Veja é um especial de 24 páginas sobre o impeachment, essa é uma edição especial sobre a crise, que aparentemente serviria, no fim das contas, para colocar o então vice-presidente na cadeira presidencial com a ajuda de personagens que agem nos bastidores, como é o caso do "mordomo" figura representada por Eduardo Cunha no texto multimodal. 
Notamos, então, que a capa contém um forte apelo visual e simbólico ao retratar Michel Temer sentado em uma espécie de assento presidencial e Eduardo Cunha vestido de mordomo. Mas, além da polêmica, quais seriam as intenções da publicação ao representar Cunha, que até então era visto como o principal “culpado" pelo processo de impeachment, como um coadjuvante? Seria então Temer responsável por orquestrar um golpe contra Dilma e seria o "assento presidencial" uma referência ao espólio almejado após o processo de impedimento? Trama digna de um episódio de House of Cards . $^{4}$

Quanto à análise da imagem, em termos representacionais, podemos perceber que os sentidos conceituais ocupam maior destaque. Percebemos um processo simbólico, pois os trajes de Eduardo Cunha foram manipulados digitalmente para posicioná-lo como uma figura Investigando representações da presidenta DilmaRousseffe dovice-presidente Michel Temer em capas de revistas nacionais sobre o impeachment serviçal e auxiliadora do ator social principal: Temer. Talvez a Carta Capital quisesse defini-lo como um aliado fiel, ou esteja referenciando uma espécie de arquétipo da literatura: o mordomo misterioso, aquele que quase sempre é responsável pelo assassinato, por exemplo.

Vale, ainda, ressaltar a relação de contato entre os participantes representados e os leitores. Ao olharmos para Temer, percebemos uma forte demanda, pois seu olhar está direcionado para o leitor, com conotação de certo desafio. Eduardo Cunha, por sua vez, olha ao longe, talvez intensificando o ar de mistério dessa figura do xadrez político nacional, até então quase desconhecida do grande público.

A Carta Capital, desde sua fundação por Mino Carta (influente jornalista brasileiro fundador de publicações como Veja, IstoÉ e Quatro Rodas), foi concebida como uma alternativa às publicações de maior tiragem. Apontado muitas vezes como "ativista" e deliberadamente político, o periódico é geralmente visto como alinhado com a esquerda. Aqui, deparamo-nos com uma tática discursiva muito utilizada pelos meios hegemônicos: a de fazer crer que apenas são ideológicos e/ou doutrinadores os discursos não hegemônicos. Quando uma narrativa tenta romper tais noções, ela é vista como perigosa e doutrinária, pois pretende modificar uma visão de mundo, contradizer "verdades" naturalizadas e consagradas.

Nesta capa, os protagonistas são Michel Temer e Eduardo Cunha, o que indica que os questionamentos irão se voltar para eles e não, para

4 House of Cards, drama político produzido pela Netflix, é uma série de TV estadunidense que acompanha Francis Underwood, um ambicioso congressista que almeja, a todo custo, o cargo máximo do Poder Executivo em seu país. 
Fábio Alexandre

Silva Bezerra

José Alves de Araújo Neto
Dilma Rousseff. O texto verbal marca a interpretação de que há uma evidente disputa pelo poder, onde Eduardo Cunha seria um subordinado de Michel Temer, executando seus planos de tomada desse poder. Temer é então representado como o "patrão rico", o detentor do poder. Tal tática discursiva parece objetivar o distanciamento do vice-presidente da maior parte da população, a qual vive em situação de subordinação e, muitas vezes, não vê com admiração os líderes que lhe são impostos.

Há duas narrativas díspares sendo difundidas por meio das representações construídas nas capas da Veja e da Carta Capital: uma que busca o impeachment e outra que alega ser um golpe tal rompimento, não sendo difícil concluir qual foi a mais disseminada, pois enquanto a Veja possui uma tiragem aproximada de 1 milhão de exemplares semanais, a Carta Capital não chega aos 200 mil. Tais números também reforçam a propagação das mensagens apenas pelas capas, pois não é difícil encontrarmos cartazes com as capas da semana da Veja em bancas de revistas, enquanto raramente encontramos a Carta Capital sendo estampada.

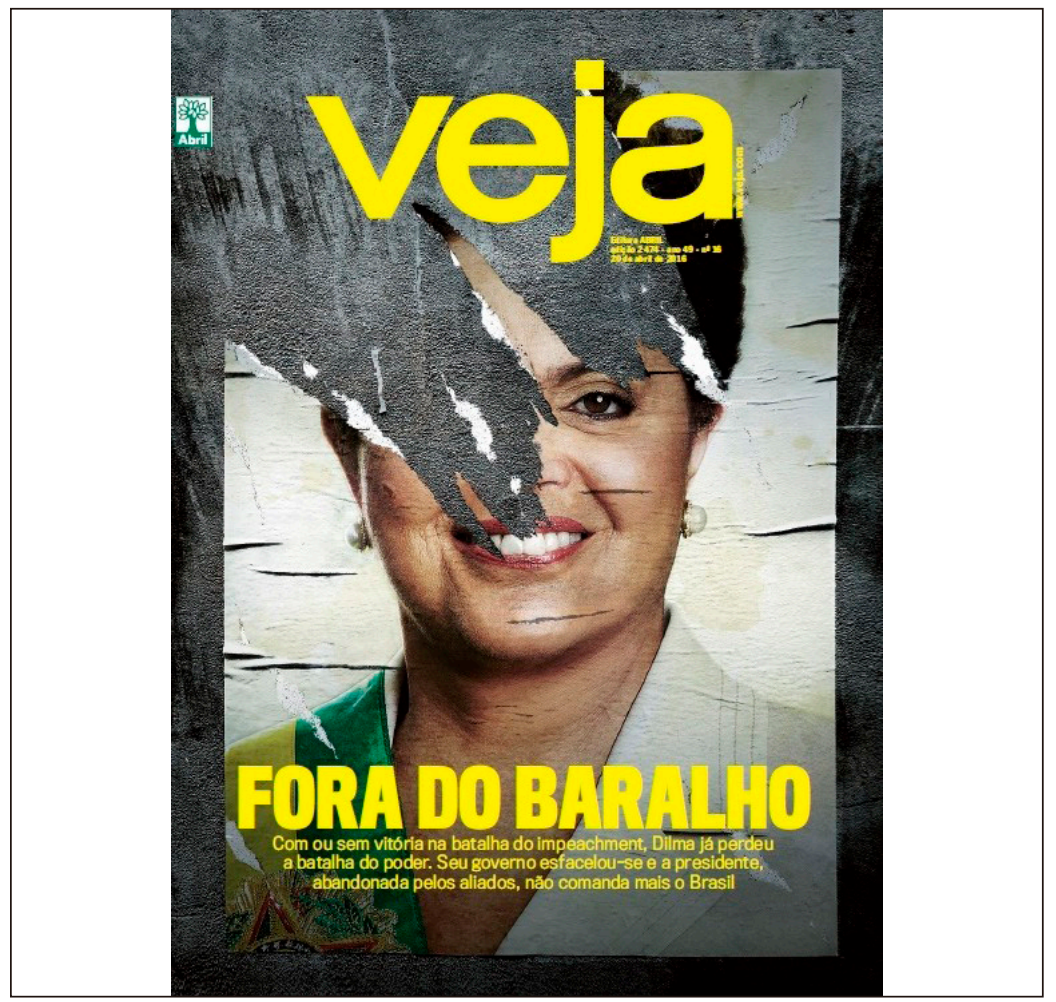

Figura 3: Capa 2 da Veja

Fonte: Página da revista na internet 
Na Figura 3, a revista Veja simula um cartaz de Dilma rasgado (pela própria população, talvez, já que ele aparenta estar em um poste), com a forte afirmação de ela já ser, nesse momento, carta "fora do baralho". Apesar de o processo de impeachment não ter sido concluído à época, a manchete afirma que, no fim das contas, isso não importa mais, pois a presidenta já perdera o comando do país em definitivo. Dilma é ilustrada por sua foto oficial de posse, rasgada, dando a entender que realmente não é mais a presidenta do Brasil e que já faz parte do passado, tendo perdido, assim, a "batalha pelo poder", apesar de ainda estar em curso a "batalha do impeachment".

Nesta capa, também vemos um foco em representação conceitual, agora por meio de um processo analítico, pois Dilma é representada apenas pelo seu busto (por se tratar de um close-up em uma foto presidencial), aumentando o impacto por ter grande parte de sua cabeça Investigando representações da presidenta DilmaRousseffe dovice-presidente Michel Temer em capas de revistas nacionais sobre o impeachment arrancada da foto. Esse fato, aliado ao rasgo na foto, também cria um processo simbólico sugestivo, visto que não é de fato um cartaz rasgado, mas, sim, uma imagem manipulada digitalmente.

Poderíamos, ainda, mesmo que com apenas um participante representado na imagem, fazer referência a um processo classificacional, pois reconhecemos facilmente ser uma foto que faz parte da Galeria Presidencial Brasileira, criando uma taxonomia implícita de Presidentes - sendo, contudo, essa presidenta a única a ter sua foto rasgada (talvez da história política do país?). No entanto, por haver sido publicada antes da conclusão do processo de impeachment, a representação multimodal da referida publicação sinaliza para um posicionamento editorial claro desfavorável a Dilma.

No dia 13 de abril daquele ano, a revista Veja publica uma matéria em seu site sobre a reunião, que havia ocorrido mais cedo, de Dilma com a imprensa. A publicação vincula uma frase de impacto, que, supostamente, foi proferida por Dilma: "Se eu perder, sou carta fora do baralho". Um dia depois, a publicação, que deveria começar a circular apenas no dia 20 (como fica claro na capa da edição), já estaria nas bancas. Em uma tática comumente utilizada pela $V e j a^{5}$, a edição semanal foi adiantada para que chegasse ao leitor antes do dia 17 (votação do impeachment na Câmara) e não três dias depois, como destaque para a manchete "Fora do Baralho".

5 Em 2014, a Veja optou por também antecipar estrategicamente uma edição em que denunciava Dilma e Lula, com claras intenções de influenciar na campanha presidencial. o Tribunal Superior Eleitoral, em liminar, proibiu a Editora Abril de veicular publicidades de tal edição e a definiu como "propaganda eleitoral", assim como decidiu por conceder direito de resposta em publicação seguinte. 
Fábio Alexandre

Silva Bezerra

José Alves de Araújo Neto
Em seu artigo "Educação para a leitura crítica da mídia”, Douglas Kellner e Jeff Share (2008) afirmam que grandes empresas de mídia podem, muitas vezes, representar um perigo à democracia, por concentrar um imenso poder de influência e dar voz apenas a um grupo seleto de pessoas, grupo este que estaria de acordo com os interesses financeiros e políticos da empresa de mídia. Como também afirma van Dijk (1995, p. 9) sobre o impacto da mídia na vida social, “esse poder (da mídia) não se restringe a sua influência sobre o público, mas também envolve seu papel dentro do quadro mais amplo do contexto social, cultural, político ou econômico das estruturas de poder da sociedade".

É importante, portanto, que estejamos sempre atentos não somente aos mecanismos discursivos em ação nos textos mais diversos, mas também à maneira como a estrutura social influencia de maneira significativa as possibilidades de representação sobre eventos sociais relevantes (MEURER, 2005), especialmente em momentos históricos que causam grandes divisões de opiniões - como é o caso em questão nesta pesquisa.

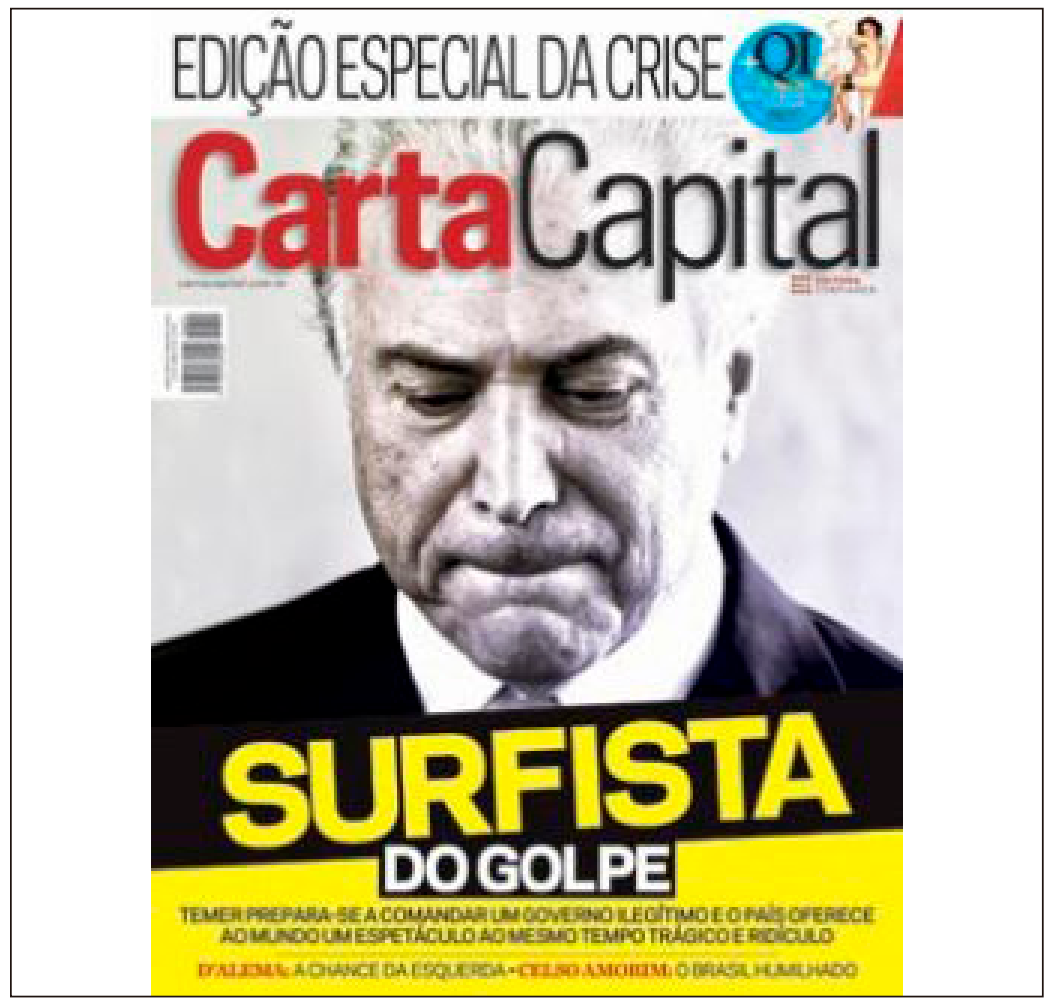

Figura 4: Capa 2 da Carta Capital

Fonte: Página da revista na internet 
Assim como a manchete da Veja (Fig. 3), a edição da Carta Capital (Fig. 4) não suaviza o tom da crítica, intitulando Temer de "surfista do golpe". 0 termo "surfista" remete à ideia de que Temer apenas "desliza nas ondas" do golpe, aproveitando-se, na verdade, da agência de outros atores sociais para "chegar até a beira-mar" (i.e. o assento presidencial). As demais palavras escolhidas para o texto de capa também são bastante fortes, como "espetáculo trágico e ridículo" e "governo ilegítimo", deixando claro o posicionamento da publicação no sentido inequívoco de construir a visão de ilegitimidade do processo de impeachment então em curso.

Temer, como "surfista do golpe", é representado como o maior beneficiado pela grave crise política do país. No entanto, apesar de sua suposta vitória, as suas feições, em close-up (distância social), também podem significar certo constrangimento perante o "espetáculo ao mesInvestigando representações dapresidenta DilmaRousseffe dovice-presidente Michel Temer em capas de revistas nacionais sobre o impeachment mo tempo trágico e ridículo" oferecido ao mundo todo. Mais uma vez, a revista exibe os dizeres "Edição Especial da Crise", o que vai de encontro à ideia de que, com Dilma "fora do baralho", a crise teria um fim, oposição que se sustenta ao observarmos os posicionamentos perceptivelmente antagônicos construídos nas capas analisadas dessas duas publicações a respeito desse momento histórico nacional.

Temer aparece na capa em uma foto preto e branco, de cabeça baixa e com expressões que podem ser entendidas como de culpa ou de arrependimento. Em termos de representações conceituais, há a construção simbólica, por meio dessas cores, da imagem de um vice-presidente com ideias ultrapassadas e voltado aos interesses conservadores da sociedade, conotando, dessa maneira, a manutenção de um status quo indesejado pela população, especialmente sua parte historicamente marginalizada. Além disso, notamos, ainda de maneira simbólica, uma representação por meio das cores amarelas e pretas, que remetem àquelas fitas zebradas de sinalização utilizadas na contenção de cenas de crimes - o que, por si só, cria uma mensagem poderosa e de impacto sobre a natureza do processo de impeachment.

No campo discursivo, enquanto a publicação semanal de maior circulação do país classifica a narrativa do golpe como "ladainha", a Carta Capital afirma que o golpe é real e que possui um novo protagonista: Michel Temer, o vice-presidente nos dois mandatos da presidenta Dilma. É importante destacar que a Carta Capital, diferentemente da Veja, não adiantou sua publicação, e no dia 26 de maio publicou a capa que estampa Michel Temer como o "surfista do golpe". 
Fábio Alexandre

Silva Bezerra

José Alves de

Araújo Neto

Um dia antes, também em seu site, a redação da revista publicou uma matéria onde constrói um paralelo entre o filme "Sem Evidências"6, em que três jovens são condenados por um crime que não cometeram, e o processo de impedimento da Presidenta. Segundo a redação, a mídia executou o papel de afervorar o ódio da população contra os réus e legitimar a decisão dos "donos do poder", que, de antemão, já haviam decidido que os jovens eram culpados, mesmo sem nenhuma prova ou evidência.

As narrativas da legitimidade do impeachment e dele como golpe estiveram presentes durante todo o processo e demonstram, sobretudo, a importância de uma leitura crítica da mídia. Para o leitor, devem estar claros os interesses políticos e financeiros de tais publicações. Por exemplo, o que leva a Carta Capital a afirmar com tanta veemência que o impeachment é um espetáculo ridículo e trágico? Quais são as intenções da Veja ao, mais uma vez, antecipar sua publicação diante de uma votação importante? As duas publicações são formadas por um conjunto de jornalistas que, certamente, são marcados por ideologias e opiniões particulares. Contudo, cabe questionarmos: seria inevitável termos publicações com posições tão enviesadas sobre o mesmo tema? Ou ambas deveriam abordar as temáticas a partir da consideração de argumentos opostos para permitir que sua audiência forme sua própria opinião com base nos fatos? Acreditamos que essa é uma discussão que precisa urgentemente ganhar mais espaço.

6 Filme de 2013 baseado em acontecimentos reais, que retrata o julgamento e a condenação (sem evidências) de três inocentes pelo crime de assassinar e estuprar três crianças. Tal sentença foi, anos depois, revogada. 


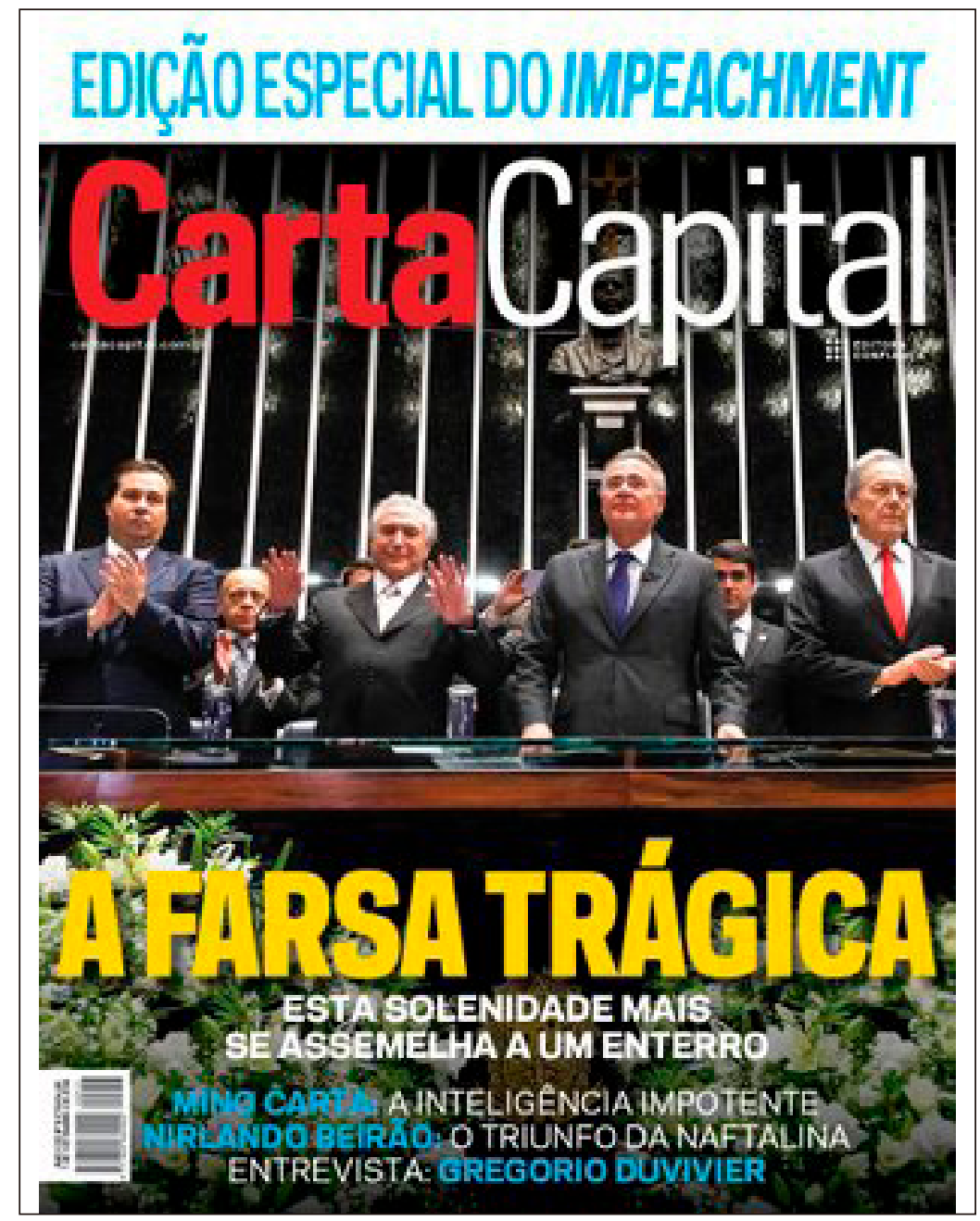

Investigando

representações

dapresidenta

DilmaRousseffe

dovice-presidente

Michel Temer em

capas derevistas

nacionais sobre o

impeachment

91

Figura 5: Capa 3 da Carta Capital

Fonte: Página da revista na internet

Após o processo de impeachment chegar ao fim, a Carta Capital exibe a edição especial intitulada de "A Farsa Trágica" (Fig. 5), farsa essa que seria o golpe disfarçado de um processo de "troca de governante incompetente". Na capa, aparecem os supostos protagonistas do golpe e seu "surfista".

Quanto às representações, o que mais se destaca é a representação narrativa. Observamos um evento em curso, simbolicamente o enterro do Partido dos Trabalhadores (PT), do mandato da presidenta Dilma, ou até mesmo da democracia. A manchete "Esta solenidade mais se assemelha a um enterro" remete às flores abaixo dos participantes e sua semelhança com coroas de flores utilizadas em enterros. 
Há, também, um processo conceitual classificacional, pois apresenta uma taxonomia implícita, por meio de grupo de políticos e ministros em visível alinhamento. Contudo, esse novo governo não parece estar próximo da população, sendo essa distância social criada por um long shot, passando uma ideia de impessoalidade. Além disso, podemos chamar atenção para a relação interacional em que os políticos se encontram em plano superior

Fábio Alexandre

Silva Bezerra

José Alves de Araújo Neto aos leitores, criando, assim, poder dos participantes representados.

$\mathrm{Na}$ imagem, vemos o "elenco" da grande farsa trágica brasileira, envolvendo, principalmente, da esquerda para a direita, Rodrigo Maia (presidente da Câmara dos Deputados), Michel Temer (a ser empossado como presidente do país), Renan Calheiros (presidente do Senado) e Ricardo Lewandowski (então presidente do Supremo Tribunal Federal). Onde estaria Eduardo Cunha, visto como o principal personagem da trama? Seria, nesse momento, também "carta fora do baralho"? O que sabemos é que ele foi afastado da presidência da Câmara por mentir em CPI e, em seguida, preso e condenado por lavagem de dinheiro, corrupção e evasão de divisas. Vale destaque também o texto verbal "o triunfo da naftalina", como possível referência ao fato de que, depois do processo de impeachment, tudo volta a ser como era antes, dentro da conhecida e velha maneira de se fazer política e permanecer no poder no nosso país.

Interessante perceber também que Farsa Trágica (The Comedy of Terrors, no original) é o nome de um filme estadunidense da década de 60 que retrata a história de um dono de funerária que, passando por dificuldades financeiras, começa a matar vizinhos para continuar pagando o aluguel e sustentar suas bebedeiras. Paralelo que, porventura, pode ser feito com a situação de Dilma, não somente por meio das imagens, mas também com base no texto verbal que afirma que "esta solenidade mais se assemelha a um enterro", já que, segundo a Carta Capital, a ex-presidenta sofreu um golpe por, dentre muitas acusações, ser a grande responsável pela crise financeira. Desta maneira, o impedimento, ou a sua "morte" política, seria uma forma que os políticos encontraram de estancar a ferida e tomar o poder. Tal como o dono da funerária passa a matar para ganhar dinheiro com os caixões, o Brasil sofreu um golpe para que a elite política pudesse voltar a dominar os rumos econômicos.

Observamos que a Veja e a Carta Capital produzem narrativas opostas com base nos mesmos fatos. Isto ocorre porque as ideologias que guiam a linha editorial das duas revistas são diferentes. Isso assume relevância destacada ao considerarmos que "o poder da mídia geralmente 
é simbólico e persuasivo, no sentido de ter principalmente potencial de controle, até certo ponto, das mentes de leitores ou espectadores, mas não diretamente de suas ações" (VAN DIJK, 1995, p. 10). Portanto, ao

Investigando representações dapresidenta DilmaRousseffe dovice-presidente Michel Temer em capas de revistas nacionais sobre o impeachment

Figura 6: Capa 3 da Veja

Fonte: Página da revista na internet 
Fábio Alexandre

Silva Bezerra

José Alves de

Araújo Neto

A autodeclarada edição histórica da Veja (Fig. 6), lançada pós-impeachment, apresenta a frequência cardíaca do país, dando destaque para o momento em que o PT começou a governar, em 2003, e implicando, com a linha reta posterior, que esse partido e seus líderes levaram o país ao estado crítico (quase morte) em que se encontra em 2016, podendo ser salvo apenas por meio de uma reanimação cardiorrespiratória (RCP) e/ou desfibrilação. Essas ações emergenciais seriam, obviamente, desempenhadas pelo novo governo "salvador da pátria". Fica claro, assim, o viés opositivo a um determinado partido politico pela revista de maior tiragem do país; no entanto, o jornalismo não deveria ser apartidário?

Percebemos, em termos representacionais, um processo simbólico: a quase morte do país, causada pelo governo do PT, com destaque para a cor vermelha em fundo preto, e pela estrela (símbolo deste partido político). Em termos composicionais, vemos que a informação conhecida (lado esquerdo) seria o PT e a informação nova (lado direito) sendo revelada pela publicação seria sua culpabilidade absoluta na situação de iminente morte do país.

Tal situação, como pode ser constatado na leitura da reportagem correspondente, seria revertida pela implementação de medidas austeras e opostas às medidas sociais e assistenciais fortalecidas e/ou criadas pelo PT, destinadas a grande parte da população. Isso revela, mais uma vez, como a mídia pode influenciar as relações de poder em determinada sociedade trazendo consequências não previstas por seus apoiadores, já que, não raro, “o conhecimento e as crenças do público são alterados em uma direção que não está necessariamente no seu melhor interesse" (VAN DIJK, 1995, p. 11).

\section{Considerações finais}

Ao discutirmos as capas de revistas analisadas, fica evidente o teor ideológico presente nesses textos multimodais. Enquanto a Carta Capital busca justificar o discurso de "golpe" e representar Temer como uma figura negativa e conspiradora, a revista Veja opta por direcionar seus ataques à figura de Dilma e reforçar a legitimidade do impeachment.

A análise das seis capas revela que seus elementos visuais e textuais têm potencial de influenciar de maneira marcante a leitura do momento histórico em questão por meio da inclusão ou exclusão de participantes, bem como pelas representações narrativas e conceituais que constroem em suas articulações multimodais a partir de objetivos específicos. 
Tais curvas ideológicas são fruto de um ambiente democrático saudável, onde diferentes discursos estão presentes. Entretanto, o alcance da grande mídia e a reprodução de um único discurso acaba por suprimir a variedade necessária dos discursos, fragilizando as discussões e doutrinando cidadãos a seguirem um único ponto de vista. Acreditamos ser responsabilidade da grande mídia a defesa dos discursos e dos contradiscursos, independente de suas visões politicas e ideológicas, permitindo, assim, que ambos possuam o mesmo alcance.

Nós, como cidadãos, precisamos estar em contato com diferentes ideologias para que então, criticamente, a discussão possa aprofundar-se em direção a uma construção individual e consciente de um ponto de vista. 0 meio de comunicação que se limita à reprodução de um único discurso dentre tantos outros aparenta muito mais estar a serviço de Investigando representações da presidenta DilmaRousseffe dovice-presidente Michel Temer em capas de revistas nacionais sobreo impeachment seus próprios interesses do que informando seus leitores sobre a realidade dos fatos. Destacamos que essa crítica pode ser direcionada para ambas as publicações pesquisadas.

O texto multimodal acaba por assumir, dessa maneira, um papel, por vezes, panfletário, ecoando o posicionamento político da publicação e ocultando sentidos que são apreendidos apenas inconscientemente por meio da repetição de certas representações em nosso cotidiano. Adotar uma postura apartidária, mais voltada para a informação baseada em fatos e argumentos sensatos, ajudaria as duas revistas a atrair novos leitores, principalmente em um cenário de tamanha polarização política. Não acreditamos que essa seja uma visão ingênua sobre o papel da mídia na sociedade, mas, sim, otimista. Afinal, sem otimismo diante das limitações humanas e estruturais, o que nos resta?

A leitura crítica multimodal, portanto, é uma ferramenta essencial para os indivíduos exercerem sua cidadania e participarem dos debates políticos, fortalecendo, assim, o ambiente democrático no qual estamos inseridos ao reforçar a importância da criticidade e ao denunciar a profunda parcialidade editorial de algumas publicações. 


\section{Referências}

BEZERRA, Fábio; NASCIMENTO, Roseli: HEBERLE, Viviane. Análise multimodal de anúncios do programa 'Na Mão Certa'. Letras (UFSM), v. 20, n. 40, 2010.

CALDAS-COULTHARD, Carmen. Da análise do discurso à análise crí-

Fábio Alexandre

Silva Bezerra

José Alves de Araújo Neto tica do discurso: introduzindo conceitos. In: ; SCLIAR-CABRAL, Leonor (Orgs.). Desvendando discursos: conceitos básicos. Florianópolis: Ed. Da UFSC, 2008, p. 19-44.

CHARADEAU, Patrick. O discurso político. In: EMEDIATO, Wander; MACHADO, Ida Lúcia; MENEZES, William (Orgs.). Análise do discurso: gêneros, comunicação e sociedade. Belo Horizonte: Núcleo de Análise do Discurso, Programa de Pós-Graduação em Estudos Linguísticos, Faculdade de Letras da UFMG, 2006, p. 251-268.

FAILLA, Zoara (Org.). Retratos da leitura no Brasil 4. Rio de Janeiro: Sextante, 2016.

FAIRCLOUGH, Norman. Critical discourse analysis. Londres, New York: Longman, 1995.

. Language and power. $3^{\text {rd. }}$ ed. Londres, Nova York: Routledge, 2015[1989].

FAIRCLOUGH, Isabela; FAIRCLOUGH, Norman. Political discourse analysis: a method for advanced students. Oxon, Londres: Routledge, 2012.

FARSA Trágica. The comedy of terrors. Direção: Jacques Tourneur. Produção: Alta Vista Productions. Roteiro: Richard Matheson. 1964. $83 \mathrm{~min}$, colorido.

FOUCAULT, Michel. A ordem do discurso. Trad. Laura F. de Almeida Sampaio. São Paulo: Loyola, 1996.

HALLIDAY, Michael; MATTHIESSEN, Christian. An introduction to functional grammar. $3^{\text {rd }}$ ed. London: Hodder Arnold, 2004. 
KELLNER, Douglas; SHARE, Jeff. Educação para a leitura critica da mídia, democracia radical e a reconstrução da educação. Educação e sociedade. Campinas, v. 29, n. 104, p. 687-715, out. 2008.

Investigando representações

KRESS, Gunther; VAN LEEUWEN, Theo. Reading images: the gramda presidenta mar of visual design. Londres, Nova York: Routledge, 2006.

DilmaRousseffe dovice-presidente MAGALHÃES, Izabel. Introdução: a análise de discurso crítica. D. E. L. T. A., 21: Especial, p. 1-9, 2005. Michel Temer em capas de revistas nacionais sobre o MEURER, José Luiz. Gêneros textuais na análise crítica de Fairclough. In: ; Bonini, A.; Motta-Roth, D. (Org.). Gêneros: teorias, métodos e debates. São Paulo: Parábola Editorial, 2005.

RESENDE, Viviane de Melo; RAMALHO, Viviane. Análise de discurso crítica. São Paulo: Contexto, 2006.

VAN DIJK, Teun A. Power and the news media. In: PALETZ, David (Ed.), Political communication in action. Cresskill, NJ: Hampton Press, 1995, p. 9-36.

. What is political discourse analysis? Belgian Journal of Linguistics, 11 Political Linguistics, Blommaert, Jan; Bulcaen, Chris (Eds.), 1997, p. 11-52.

Political discourse and ideology. In: LORDA, Clara; RIBAS, Montserrat (Eds.), Anàlisi del discurs polític. Barcelona: Universitat Pompeu Fabra, IULA, 2002, p. 15-34.

WODAK, Ruth. The politics of fear: what right-wing populist discourses mean. London: Sage, 2015.

\section{Revistas Consultadas}

CARTA CAPITAL. Confiança, edição 897, 15 abril 2016.

Confiança, edição 899, 20 abril 2016.

. Confiança, edição 917, 01 setembro 2016. 
VEJA. São Paulo: Abril, edição 2455, ano 48, n. 49, 09 dezembro 2015. . São Paulo: Abril, edição 2474, ano 49, n. 16, 20 abril 2016. . São Paulo: Abril, edição 2494, ano 49, n. 36, 07 setembro 2016.

Fábio Alexandre

Silva Bezerra $\quad$ Recebido em fevereiro de 2018

Aceito em abril de 2018

José Alves de

Araújo Neto

98 